\title{
XI DE AGOSTO
}

\author{
Antonio Junqueira de Azevedo \\ Professor Titular do Departamento de Direito Civil da \\ Faculdade de Direito da Universidade de São Paulo
}

Tratando-se da comemoração do centésimo septuagésimo segundo ano da fundação dos cursos jurídicos, não podemos deixar de dar uma visão retrospectiva, que nos transporte àquele longínquo ano de 1827. O que acontecia então no mundo? Como estava o Brasil?

Todavia, a limitação desta exposição a somente essa época seria extremamente frustrante, especialmente aos alunos aqui presentes, porque a verdade é que "XI de Agosto" é frase que sofreu evolução semântica e, hoje, no Brasil inteiro, significa também o Centro Acadêmico. Parece-me, assim, adequado que, num segundo momento, nos remontemos ao final do século passado e começo deste - quando o Centro Acadêmico XI de Agosto foi fundado -, examinando o que também então se passava.

Finalmente, para os jovens de espírito, e para mim mesmo, seria motivo de decepção, tratar desta data tão importante, e no limiar do terceiro milênio, se permanecêssemos no passado, sem olhar em torno e procurar projetar o que desejamos para a Faculdade, no futuro.

Eis aí, pois, o esquema, ainda que sem unidade, em três etapas, do que pretendemos desenvolver: uma visão do tempo da fundação dos cursos jurídicos; um apanhado do que aqui se passava há cem anos, quando se fundou o Centro Acadêmico; e o que se pode prever e desejar para o futuro.

Pesquisando o ano de 1827, quando se vivia no ethos do liberalismo romântico, verificamos que não foi ele, na História Universal, um ano especialmente fecundo de grandes acontecimentos políticos - tomando sempre por critério, como é lógico, as conseqüências dos acontecimentos mundiais para a formação brasileira.

A Grécia tentava se libertar da Turquia - que, por isso, sofria pressão da França e da Inglaterra. Os russos, em guerra com os persas, tomaram Erivan, na

\footnotetext{
* Discurso proferido na Sala da Congregação por designação da Diretora da Faculdade de Direito da Universidade de São Paulo, em 11 de agosto de 1999.
} 
Armênia. O dey de Alger ofendeu ao cônsul da França, batendo-lhe no rosto com 0 leque - e isto acabaria por levar à colonização francesa da Argélia. Nada disso nos toca diretamente. Mais perto: o Peru se separava da Colômbia e, em Portugal, davase a oficialização do noivado de D. Maria II (em favor de quem D. Pedro I abdicara, após a morte de D. João VI, em 1826), com D. Miguel, que se torna regente (proclamar-se-ia rei, em 1828). Esses últimos fatos, como se sabe, influirão na futura abdicação (1831) do nosso primeiro imperador.

$\mathrm{O}$ ano de 1827. queremos crer, foi ano importante na literatura. Vitor Hugo, certamente um dos maiores escritores franceses, publicou "Cromwell" e seu famoso "Prefácio" que renovou o teatro mundial, abolindo o teatro clássico com sua regra das três unidades (lugar, tempo e ação). Heine publica o "Livro dos Cantos" ("Buch der Lieder"), que viria influenciar, muitos anos depois, um dos filhos diletos da Casa, Castro Alves. Manzoni publica a versão final de uma das mais importantes obras da literatura italiana, "I Promessi Sposi"

Até nas artes plásticas, suas manifestações, vistas a longo prazo, parecem mais importantes que os acontecimentos políticos: Ingres apresenta a Apoteose de Homero" hoje no Louvre; Delacroix e Corot também se salientam.

Um incidente político, aparentemente menor, parece-nos, porém, muito significativo. É que começava, então, a tomar vulto a importância da imprensa na opinião pública e houve a primeira tentativa de censura estatal; a lei francesa, "Loi de la justice et de l'amour" estabelecia a censura prévia. ${ }^{1}$ Afinal, apesar de inicialmente aprovada, a lei, por pressão popular, terminou rejeitada em 1827. Esses fatos da história francesa, de certa forma, se repetirão em São Paulo - sempre com algum atraso.

Aqui, pois, qual era a situação? O primeiro jornal que aparece entre nós, "O Paulista" bi-semanário, data de 1823, e era manuscrito! Era dirigido por Azevedo Marques, o "mestrinho" 2 Foi somente em 1827, ano da fundação dos cursos jurídicos, que apareceu o primeiro jornal impresso, em São Paulo: "Farol Paulistano" Também, somente então, tivemos a primeira tipografia - depois da Bahia, Rio, Maranhão, Ceará, Pará, Pernambuco!

Biblioteca pública, somente tivemos em 1825 - formada pelo presidente da Província de São Paulo com livros do bispo Dom Mateus e que

1. Cf. Michel Mourre, "Dictionaire Encyclopédique d'Histoire", Paris, Bordes, 1978.

2. Aureliano Leite, "História da Civilização Paulista", São Paulo, Saraiva, 1954, p. 131. 
passaria, depois, para a Faculdade de Direito, ${ }^{3}$ daí, os velhos livros religiosos, inclusive 12 bíblias, que até hoje se encontram na biblioteca da Faculdade.

$\mathrm{O}$ fato é que a Província de São Paulo não tinha sido favorecida pelo séc. XVIII; nossa população, em 1827, era pequena, por força da migração, no século anterior, para Minas Gerais. Segundo Saint Hilaire, a Província toda, incluindo, então, o Paraná, tinha 258.901 habitantes (sendo, mais ou menos $2 / 3$ de pessoas livres, portanto, mais ou menos 173 mil livres). A cidade era atrasada, não tinha hotéis, as ruas eram sem calçamento, - e é de admirar que tivesse sido decidido haver cursos jurídicos em São Paulo. De 1772 a 1827. São Paulo enviou a Coimbra apenas 37 estudantes, enquanto Minas Gerais, $164 .^{4}$ Especialmente os deputados baianos e mineiros - estes queriam S. João Del Rey - haviam se oposto a instalação dos cursos jurídicos em São Paulo. Diziam que o dialeto de São Paulo era o pior do Brasili ${ }^{5}$ que São Paulo não tinha edifícios próprios para uma universidade, "a cidade (é) tão pequena que nem os estudantes acharão casas para viver" (Casimiro da Cunha).

Apesar disso, como se sabe, os cursos se instalaram e as aulas se iniciaram em $1^{\circ}$ de março de 1828 (antes da nossa co-irmã de Olinda e Recife, cujos cursos somente começaram em abril). A partir daí, tem início a "virada" que levaria São Paulo a ter enorme importância no Brasil, já no final do século. Para finalizar esse periodo de liberalismo romântico, lembremos que, depois do jornal "Farol Paulistano" Líbero Badaró, em 1829, fundou o "Observador Constitucional" que, com críticas violentas ao governo central, viria a ser causa de seu assassínio. Pinto Júnior, cujo pai acudiu o ferido e é testemunha do tempo, escreveu: ${ }^{6}$ "A noticia de que o dr. Badaró tinha sido assassinado correu como uma centelha elétrica e minutos depois um numeroso concurso de estudantes de Direito corria a chamar nosso prezado pai, o cirurgião-mor Joaquim Antonio Pinto, para que fosse prestar os socorros da ciência ao seu infeliz colega; nós o acompanhamos, e ao chegar à pequena casa térrea em que habitava a vítima, na rua $S$. José, - é hoje a rua Libero Badaró - dificilmente pudemos atravessar a onda de povo, que literalmente enchia

3. Aureliano Leite, ob. cit., p. 133

4. Aureliano Leite, ob. cit., p. 136

5. Silva Lisboa, apud Almeida Nogueira, "Tradições e Reminiscências" $1^{2}$ série, s.c.p., São Paulo, 1908, p. 11.

6. Apud Almeida Nogueira, ob. cit., $5^{\text {a }}$ série, p. 9. 
a rua. Badaró estava deitado sobre o leito, pálido, com essa palidez da morte que Ihe estava próxima, a larga fronte banhada em um suor frio, o pulso letal, mas o rosto sereno e a palavra sonora" Depois, continua Almeida Nogueira: "Deu-se o óbito no dia seguinte, exatamente 24 horas depois do atentado. Refere a tradição que, no seu leito de morte, aludindo às conseqüências do atentado, Badaró dissera: 'Morre um liberal, mas não morre a liberdade'" São as palavras que estão em seu túmulo, no cemitério da Consolação. Os estudantes exigiram punição.

Passemos, porém, sem mais, ao final do século passado, segundo momento de nossa exposição.

De 1870 a 1889, tivemos, certamente, o melhor tempo da Faculdade; foi a época da campanha abolicionista, com união dos estudantes e professores, irmanados na nobre causa. Aureliano Leite cita, desse período, setenta grandes nomes do Império, que cursaram a Faculdade. Fiéis, porém, ao que prometemos de início, passaremos diretamente a cem atrás, 1899.

Na verdade, desde a proclamação da República, a mágica estava desfeita e o clima de união cívica entre estudantes e professores já não existia. Havia, depois de 1889, vários professores que continuaram monarquistas, ao contrário dos estudantes, quase todos republicanos. Alguns atritos ocorreram. Em 1890, o professor Justino de Andrade, em incontida explosão em favor da monarquia, indispôs-se com os alunos e acabou jubilado pelo Marechal Deodoro. Seu irmão e o professor Sá e Benevides, em solidariedade, requereram jubilação.

Em 1891, a Congregação da Faculdade, por sua vez, tomou posição radicalmente republicana e negou moção de pesar pela morte de D. Pedro II, ocorrida em hotel de Paris. Aureliano Leite, de quem estamos tirando esses dados, chama de "modesto hotel" mas o hotel era o Hotel Bedford, que existe até hoje, à rue L'Arcade, 17. e que está classificado como "grand confort" no atual Guia Michelin (equivale a "top class" em inglês, ou "gran confort" em italiano; é o segundo tipo de hotel do Guia Michelin, portanto, 4 estrelas). A proposta da moção de pesar fora feita por João Mendes de Almeida Jr. (cujo pai, Mendes de Almeida, o velho, também era monarquista). Todavia, no ano seguinte (1892) - vale acrescentar em prol da Congregação -, esse colegiado, demonstrando independência de espírito, deu parecer a favor da princesa Isabel e da princesa Leopoldina, sobre os bens dotais que o Governo Federal queria fazer reverter à nação (parecer dos profs. Barão de Ramalho, Mamede de Freitas e Oliveira Lima). Esse parecer consta da Revista da Faculdade, em seu primeiro número, que é de 1893. 
No final do século, a situação paulista, em relação aos demais estados brasileiros, já havia mudado em 180 graus. É, então, que Silveira Martins, grande político gaúcho, tendo vindo a São Paulo para lançar um partido parlamentarista, apesar de bem recebido, tem a célebre frase que ilustra a situação de São Paulo: "Os paulistas são ricos; não servem para a luta. Não querem arriscar suas comodidades"

Estatisticamente, a população do Estado, em 1900, era de $2.282 \mathrm{mil}$ pessoas - menos que a população de Paris mas muito mais que os 258.901, de 1827; a população decuplicara em setenta anos. Já então $66 \%$ da exportação nacional é paulista. Nesse ano (1900), a população do Estado é a $2^{\mathrm{a}}$ do Brasil (a $1^{\mathrm{a}}$ é de Minas Gerais e a 3a , da Bahia); São Paulo é o Estado que tem maior orçamento. A população total brasileira, deveria ser mais ou menos de 15.000.000 pessoas $^{7}$ (para eventual comparação com os tempos atuais, lembramos que a população européia, nessa época, já era de 400 milhões de habitantes).

A razão da grande virada, durante o século XIX, a favor de São Paulo, no contexto brasileiro, está na imigração, quanto à população, e no café, quanto à riqueza. De 1827 a 1899, São Paulo recebeu 86.117 imigrantes portugueses, 578.308 italianos (de 1870 a 1899), 92.869 espanhóis, 17.676 austríacos e 38.316, outros (incluindo alemães), resultando num total de 813.286 imigrantes. $^{8}$

Cumpre lembrar que, até essa data, não entraram japoneses no Estado, eis que estes somente vieram a partir de 1908. Vale dizer também que, a partir de 1900, diminuiu consideravelmente o número de ingressos de italianos (em 1902, na Itália, o decreto Prinetti, chegou a proibir a emigração para o Brasil. ${ }^{9} \mathrm{O}$ Estado de São Paulo gastou muito com a imigração ${ }^{10}$ - ao contrário do que foi gasto com os negros, o que é uma injustiça histórica até hoje não reparada. ${ }^{11} \mathrm{O}$ Estado de São Paulo, até 1932, recebeu 2.624.136 imigrantes.

$\mathrm{Na}$ época de que estamos tratando - final do séc. XIX e começo deste -, tudo que é moderno já existe. É o início do século da eletricidade, por oposição ao

7. Cf. Hélio Vianna, "História do Brasil", 5a ed., São Paulo, Melhoramento, 1967, p. 153, que dá 14 milhōes por ano no ano da Proclamaçāo da República.

8. Alfredo Elis Jr., "Populações Paulistas", São Paulo, Companhia Editora Nacional, 1934, p. 69.

9. Apud Hélio Vianna, obra citada, p. 276.

10. Cf. Elis Jr., obra citada.

11. Vide nosso artigo no Jornal da USP, ano XV, n. 487. 
século do vapor, o anterior. Outros pontos: já há metrô em Paris (desde 1898); a Copa Davis é disputada, pela primeira vez, em 1900; o box é reconhecido como esporte, em 1901; o primeiro submarino inglês é de 1901. Em 1906, Paris tem 2,7 milhões de habitantes; Londres 4,5 milhões; Nova Iorque, 4 milhões; Berlim, 2 milhões; Tóquio 1,9 milhões; Viena, 1,3 milhões. ${ }^{12}$

Em 1900, a mesma "vida moderna" também existe em São Paulo. O primeiro jogo público de futebol - esporte introduzido por Charles Miller, inglês mas nascido em São Paulo - deu-se em 1885, entre o "São Paulo Atlético" e o "São Paulo Railway" Em 1900, tivemos o primeiro bonde elétrico (Light). Há alguns automóveis, sendo o primeiro, de 1893, da família de Henrique Santos Dumont. O Clube Atlético Paulistano é de 1900.

Em 1898, matriculou-se a primeira mulher na Faculdade, Da. Maria Augusta Saraiva. Colou grau em 1902, quando um grande jornal, dando a informação, não reconheceu os novos tempos e escreveu: 'não desejar ver seu exemplo seguido por nossas noivas, irmãs ou filhas"! $!^{13}$ Advogada criminalista, nesse mesmo ano, ela atuou no júri (chegou a fazer 50 anos de formada).

Quanto aos estudantes da Faculdade, é o seu grande momento. Os estudantes estão, então, muito ativos. Em 1901, por exemplo, houve choque entre estudantes e a Polícia, sendo ministro Epitácio Pessoa, de quem se fez o enterro simbólico. Em 1902, na colação de grau, o bacharelando Armando da Silva Prado discursa, chamando atenção para a questão social, o que teve grande repercussão. Finalmente, em 1903, o Centro Acadêmico é fundado, sendo seu primeiro presidente, Pedro de Sampaio Dória.

Pode-se dizer que, a partir daí, os estudantes do "XI" se tornam "nacionais" São procurados pelos mais importantes políticos do País. Em 1905, após encontro com Pinheiro Machado, lançam a candidatura de Campos Sales à presidência da República (seria para seu segundo mandato). $O$ resto do país se une em torno do brado "basta de São Paulo" e é, então, lançada a candidatura de Afonso Pena (1905) - que, aliás, foi aluno da Casa e que teve apoio dos alunos mineiros da Faculdade. Campos Sales desistiu da candidatura e Afonso Pena, como se sabe, foi eleito (mandato de 1906 a 1909).

12. "The Timetables of History", $3^{2}$ ed., Nova Iorque, Simon \& Schuster/Touchstone, 1991, ano de 1906, G.

13. Aureliano Leite, obra citada, p. 261. 
Antes de passarmos aos tempos de hoje, lembremos somente um fato da Faculdade, de 1905. Pedro Lessa, professor sério e culto, causou "inominável escândalo" ao aprovar todos os alunos com distinção. Na verdade, queria com o gesto, protestar contra as condições de ensino. Esta circunstância seria um bom traço-de-união para os tempos de hoje, terceira etapa de nossa exposição. Outro, que preferimos aqui, seria a chamada "questão social" já que também ela vem daquele final de século (o jornal "O Socialista" em São Paulo, é de $1896^{14}$ e, em julho de 1903, ano da fundação do "XI" houve a primeira greve geral em São Paulo - greve de cocheiros e carroceiros). Ora, a questão social acabou levando a uma mudança de paradigma jurídico. Passemos, pois, a esse ponto e ao terceiro momento desta exposição.

"Paradigma" significa "modelo" "exemplo" "padrão" (Caldas Aulete). É especialmente "tipo de declinação ou conjugação"; por exemplo, o paradigma da primeira declinação, em latim, é rosa (rosa, rosa, rosae, rosae, rosa, rosam); o da primeira conjugação é laudare (laudo, laudas, laudat, laudamus, laudatis, laudant); etc. Aqui, porém, estamos querendo nos referir a "paradigma" como conceituado por Kuhn, em livro de 1977, A Estrutura das Revoluçồes Científicas" É tese de Kuhn que as revoluções científicas se processam por mudanças de paradigmas, isto é, de "modelos de problemas e soluções para uma comunidade de operadores" Nada mais adequado ao Direito, em que seus atores (juízes, advogados, promotores) passam, de geração em geração, o conhecimento quer de casos de conflitos quer do modo como esses casos foram, ou devem ser, resolvidos. A própria lei é expressão de um conflito e sua solução.

No campo do Direito, o paradigma do final do século era o liberalismo econômico, isto é, da lei (a lei "rígida"). O valor mais importante era o da segurança jurídica e, para obter esse desideratum, a lei deveria ser universal, geral - para todos as pessoas sem exclusão; abstrata - para todos os casos, sem distinguir "excepcionalidades"; precisa, - com fattispecie, ou hipótese, bem definida; inteira, sem lacunas. O papel do juiz era de um autômato, "la bouche de la loi"; a sentença, um silogismo; etc.

A questão social acabou, porém, levando o direito ocidental a uma mudança de paradigma. Passou-se da lei, ao paradigma do Estado e do juiz. Os problemas jurídicos, a partir de então, progressivamente, passaram a ser 
solucionados pelo juiz, por preenchimento de conceitos jurídicos indeterminados, concretização de cláusulas gerais, como a de boa fé, - a ponto de se falar em "fuga para as cláusulas gerais" - e utilização de uma axiologia formal, em que avultam conceitos vagos como "interesse público" "função social" "ordem pública" É o tempo do Estado interventor e do Direito Público. Isto significa, historicamente, que, depois do direito civil, no tempo do liberalismo romântico, passou-se ao Direito Comercial, no tempo do liberalismo econômico e, daí, ao Direito Administrativo e Processual, nesse tempo do paradigma "moderno" (modernista).

Mas, e hoje? Hoje, vivemos os tempos do pós-moderno. O Estado não tem mais nem o monopólio da norma, como legislador, nem o da decisão, como juiz. Voltamos, com força, ao Direito Privado. A própria lei é negociada e, no lugar da sentença, há arbitragem. Há também muitas decisões de órgãos à margem do Poder Judiciário, como as da justiça desportiva, do Conselho Monetário, das Bolsas de Valores, do CADE e dos organismos profissionais (OAB, Conselhos de Medicina). Da fuga para o juiz (tempos modernistas), passamos à fuga do juiz (tempos pósmodernos).

Além disso, códigos longos e com muitos temas ficaram ultrapassados. Também os velhos conceitos da axiologia formal não mais satisfazem; a própria Constituição da República, por exemplo, abandonou o caráter vago de expressão "função social" Também uma cláusula geral, como a de boa-fé, tem, na doutrina, na jurisprudência e nas leis ou códigos realmente mais novos, seu conteúdo devidamente precisado - há procura de atendimento às expectativas criadas na outra parte, em correspondência com o investimento feito.

$\mathrm{Na}$ área mais ampla da intelectualidade em geral, a que o direito não pode ficar alheio, estamos também a notar mudança de paradigma. Conforme 0 neopragmatismo de Rorty, os conceitos são encarados como instrumentais; a mente não é um reflexo da natureza. Todo conceito lógico é "making" isto é, conceito feito pela mente, e não, "finding" isto é, encontrado. Portanto, o critério "falso/verdadeiro" deve ser colocado de lado; a exata correspondência com a realidade não existe, o conceito não é reprodução da realidade, e sim, algo, repetimos, feito pela mente para uso da própria mente. Logo, o critério falso/verdadeiro deve ser substituído, no campo lógico (não, no ético), pelo critério "mais útil/menos útil" Paralelamente, a antropologia, a paleotologia e a biologia já não permitem fazer separação radical entre o homem e o resto da natureza; as citadas ciências, no seu estágio atual, puseram abaixo a concepção rígida, refletida no 
direito, do homem como único sujeito de Direito e tudo o mais - incluindo nossos primos, os macacos, - como objeto de direito. Aumentou enormemente a preocupação com a vida; assim, depois do Direito do Consumidor, é o Direito Ambiental que, agora, procura encontrar seu lugar no quadro das disciplinas jurídicas. A verdade é que muitas idéias do paradigma modernista, como a da "grande família humana" tal qual se expressa a "Declaração Universal dos Direitos Humanos" de 1948, ou a de "pessoa humana como um absoluto" estão a sofrer um forte abalo diante da concepção da vida, como movimento contínuo, que passa de um ser a outro, desde quatro bilhões de anos atrás. Sob essa perspectiva, não há razão para tanto orgulho humano: nós, como os outros seres vivos, estamos aí na condição de meros suportes para a vida - uma vida cósmica. Um radical diria: para a vida na terra, somos meio e não, fim. $\mathrm{O}$ antropocentrismo modernista está sendo derrotado pelo biocentrismo pós-moderno (é claro que, do ponto de vista religioso, a Graça pode nos tirar deste ciclo de vida imanente e nos colocar na vida transcendente; aí, de fato, seremos fim, e não meio, mas, sobre isto, neste momento e nesse local, não nos compete dissertar).

De um ponto de vista mais terra-a-terra, o que importa é dizer que a pós-modernidade está aí e para nós - funcionários, alunos e professores da Faculdade de Direito -, não vale a pena chorarmos pelo que acabou. É preferível reconhecermos a situação, e agirmos sobre ela, que fechar os olhos; a defesa da vida é uma boa causa. É uma oportunidade para voltarmos aos tempos áureos e nos unirmos. Ajudemos o parto de um mundo novo e entremos confiantes no terceiro milênio.

São Paulo, 11 de agosto de 1999. 